\title{
Ultrafast Phosphazene-Promoted Controlled Anionic Polymerization of Styrenic Monomers
}

\section{Konstantinos Ntetsikas, ${ }^{1}$ George Polymeropoulos, ${ }^{1}$ George Zapsas, ${ }^{1}$ Panayiotis Bilalis, Yves Gnanou, ${ }^{2}$ Nikos Hadjichristidis ${ }^{1}{ }^{1}$}

${ }^{1}$ Physical Sciences and Engineering Division, KAUST Catalysis Center, Polymer Synthesis Laboratory, King Abdullah University of Science and Technology (KAUST), Thuwal 23955, Saudi Arabia

${ }^{2}$ Physical Sciences and Engineering Division, King Abdullah University of Science and Technology (KAUST), Thuwal 23955, Saudi Arabia

Correspondence to: N. Hadjichristidis (E-mail: nikolaos.hadjichristidis@kaust.edu.sa)

Received 30 August 2018; accepted 27 September 2018

DOI: 10.1002/pola.29258

ABSTRACT: The anionic polymerization of styrenic monomers with phosphazene bases as promoters, utilizing "seeding" technique in a nonpolar solvent and at room temperature was studied. In all experiments, the phosphazene base $\left(t-\mathrm{BuP}_{4}, t-\mathrm{BuP}_{2}\right.$, and $\left.t-\mathrm{BuP}_{1}\right)$ was added in an equimolar amount to the organolithium initiator after the formation of oligomers $(2 \mathrm{~min}$ ) by conventional anionic polymerization. When $t-\mathrm{BuP}_{4}$ was used, the polymerization of styrene and 4-methylstyrene was extremely fast (100\% conversion within $5 \mathrm{~min}$ ) and the final homopolymers exhibited narrow molecular weight distribution and controlled molecular characteristics.
Likewise, when weaker bases were employed, the polymerization was also controlled but showing slower reaction rate. To examine the "livingness" of this system, block copolymers were synthesized by sequential monomer addition. Further studies were conducted in order to extend this novel method to the anionic polymerization of dienes. (C) 2018 Wiley Periodicals, Inc. J. Polym. Sci., Part A: Polym. Chem. 2018

KEYWORDS: anionic polymerization; block copolymers; phosphazene superbases; seeding; styrenic monomers
INTRODUCTION Living anionic polymerization was discovered and reported in two seminal papers ${ }^{1,2}$ by Szwarc et al., working on the polymerization of styrene with sodium naphthalenide as initiator, in tetrahydrofuran (THF). Since its discovery, it has emerged as the most powerful tool for the synthesis of well-defined polymers with narrow molecular weight distribution and controlled molecular characteristics (molecular weight, composition, microstructure, and architecture). ${ }^{3-5}$ The ability of anionic polymerization to produce well-defined polymers is mainly due to the absence of termination and chaintransfer reactions. ${ }^{6,7}$ In addition, it inspired many researchers to develop controlled/living strategies for monomers which are not compatible with anionic polymerization. ${ }^{8}$

The unique aspect of control in living anionic polymerization motivated tremendous academic and industrial research activity which led to the development of numerous technologies reflected in important commodity and specialized materials. ${ }^{9}$ Although anionic polymerization is a demanding methodology and cannot tolerate many functional groups, it works exceptionally well with important monomers such as styrene, 1,3-butadiene, and isoprene, that are found in many commercial applications. ${ }^{10}$ It holds a leader position in the industrial production of polydiene rubbers, styrene/butadiene rubbers, and thermoplastic elastomers of styrenic type that are used in numerous industries such as automotive, building and construction, footwear, medical, wires, and cables. ${ }^{4,11,12}$

Anionic polymerization proceeds via organometallic sites, carbanions (or oxanions) with metallic counterions. Among others, organolithiums are the most widely used initiators. ${ }^{13}$ The main requirement for the employment of an organometallic compound as the initiator is its rapid reaction with the monomer at the initiation step of the polymerization, and specifically with a higher reaction rate than the propagation step. Slow initiation followed by rapid propagation broadens the molecular weight distribution of the resulting polymers. This undesired broadening can be eliminated by the use of the "seeding" technique. ${ }^{14-16}$ In this method, the initiator is reacted with a small amount of monomer, the mixture is left for a while to form oligomers and subsequently, the rest of the monomer is added. These oligomers will grow uniformly upon addition of the remaining monomer and produce polymers with narrow molecular weight distribution. ${ }^{17}$

It is widely known that the rate of polymerization of styrene initiated by carbanionic initiators is accelerated in the presence of additives such as Lewis bases (ethers or amines). ${ }^{18,19}$ 


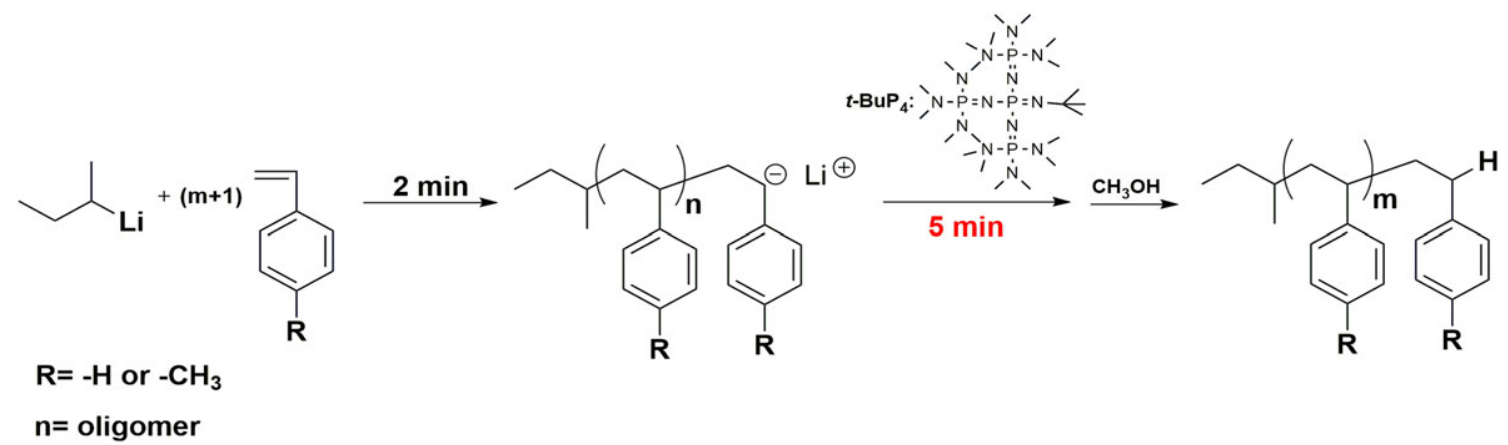

SCHEME 1 General reactions for the anionic polymerization of styrenic derivatives via "seeding" technique in the presence of $t$-BuP 4 . [Color figure can be viewed at wileyonlinelibrary.com]

In general, additives exhibit high solvating power and can induce the solvation of ion pairs. Moreover, they cause the disaggregation of aggregated ion pairs and are used either for fast initiation or to accelerate the rate of polymerization of several monomers. ${ }^{20}$ Especially, in the case of polydienes (polybutadiene and polyisoprene), additives can alter the microstructure of the final polymers, enhancing their vinyl content. ${ }^{21,22}$

In addition to ethers and amines, phosphazene superbases, a category of neutral Brönsted bases ${ }^{23,24}$ have been used as additives in anionic polymerization ${ }^{25,26}$ and more extensively as effective organic catalysts for the polymerization of several types of heterocyclic monomers (epoxides, cyclosiloxanes, cyclic esters, etc.). ${ }^{273}$ The main feature of these non-nucleophilic bases is their high basicity $\left(26<\mathrm{p} K_{\mathrm{a}}<43\right.$ in acetonitrile). The increase in basicity is proportional to the number of $\mathrm{P}$ atoms, due to a rise in the delocalization of the charge on the conjugated phosphazenium cation. ${ }^{34}$ In general, phosphazene bases enhance the nucleophilicity of the initiator/chain-end significantly by complexation with the counterion (e.g., proton or lithium cation), resulting in a rapid anionic polymerization. ${ }^{35}$

In our previous work, we investigated the anionic polymerization of styrene and 1,3-butadiene utilizing different phosphazene bases $\left(t-\mathrm{BuP}_{1}, t-\mathrm{BuP}_{2}\right.$, and $t$ - $\left.\mathrm{BuP}_{4}\right)$ as organic catalysts in a nonpolar solvent at room temperature. ${ }^{25}$ When $t$-BuP $\mathrm{P}_{1}$ was used, the polymerization proceeded in a controlled manner, whereas the obtained homopolymers exhibited the desired molecular weights and narrow polydispersity $(\theta<1.05)$. In the case of $t$ - $\mathrm{BuP}_{2}$, homopolymers with higher molecular weights than the theoretical ones and relatively low polydispersity were obtained. Finally, in the presence of $t$-BuP 4 , the polymerization of styrene was uncontrolled due to the high reactivity of the formed carbanions. In this work, we report the "seeding" technique, to tap the ultrafast anionic polymerization of styrene and 4-methylstyrene (4MS) using $t$-BuP 4 as promoter in a non-polar solvent at room temperature via high vacuum techniques. In addition, we studied the anionic polymerization of styrene with other phosphazene bases $\left(t-\mathrm{BuP}_{1}\right.$ and $\left.t-\mathrm{BuP}_{2}\right)$ and explored the "livingness" of these systems by synthesizing block copolymers with styrene and 1,3-butadiene. This strategy of "seeding" technique led to the one-pot synthesis of well-defined homopolymers and copolymers with controlled molecular characteristics.

\section{EXPERIMENTAL}

\section{Materials}

1-tert-Butyl-4,4,4-tris(dimethylamino)-2,2-bis[tris(dimethylamino) phosphoranyli-denamino] $-2 \lambda^{5}, 4 \lambda^{5}$-catenadi-(phosphazene) $(t$-BuP $4,0.8 \mathrm{M}$ in hexane, Sigma-Aldrich, Al-Khobar, Saudi Arabia), 1-tert-butyl-2,2,4,4,4-pentakis(dimethylamino)- $2 \lambda^{5}, 4 \lambda^{5}$-catenadi(phosphazene) $\left(t-\mathrm{BuP}_{2}, 2.0 \mathrm{M}\right.$ in THF, Sigma-Aldrich) and tertbutylimino-tris(dimethylamino)phosphorane $\left(t-\mathrm{BuP}_{1}\right.$, Sigma-Aldrich, 97\%) were used as received. sec-Butyllithium (1.4 M in cyclohexane, Sigma-Aldrich) was diluted to an appropriate concentration in purified benzene, in a specific glass apparatus. Styrene (Sigma-Aldrich, 99\%) and 4MS (Sigma-Aldrich, 96\%) were purified via consecutive distillations over $\mathrm{CaH}_{2}$ (SigmaAldrich, 95\%) and dibutyl-magnesium (1 M in heptane, SigmaAldrich) and stored in precalibrated ampoules. 1,3-Butadiene (Sigma-Aldrich, 99\%) was purified via consecutive distillations over $n$-BuLi, at $-10{ }^{\circ} \mathrm{C}$ using ice/salt bath, prior addition to the polymerization reactor. Benzene (Sigma-Aldrich, 99.8\%) was purified via distillation from $\mathrm{CaH}_{2}$ and stored in round-bottom

TABLE 1 Molecular Characteristics of PS Synthesized by Anionic Polymerization and Use of $t$-BuP 4 via "Seeding"

\begin{tabular}{|c|c|c|c|c|c|c|}
\hline Entry & Sample & $t-\mathrm{BuP}_{4} / \mathrm{sec}-\mathrm{BuLi}^{\mathrm{a}}$ & $M_{\mathrm{n}}^{\text {target }}\left(\mathrm{g} \mathrm{mol}^{-1}\right)$ & $M_{\mathrm{n}}^{\mathrm{b}}\left(\mathrm{g} \mathrm{mol}^{-1}\right)$ & $\theta^{\mathrm{b}}$ & Time (After Addition of $\left.t-\mathrm{BuP}_{4}\right)(\mathrm{min})$ \\
\hline 1 & PS-1 & $1: 1$ & 7000 & 7200 & 1.11 & 5 \\
\hline 2 & PS-2 & $1: 1$ & 20,000 & 21,400 & 1.10 & 5 \\
\hline 3 & PS-3 & $1: 1$ & 45,000 & 45,500 & 1.08 & 5 \\
\hline
\end{tabular}


(A)

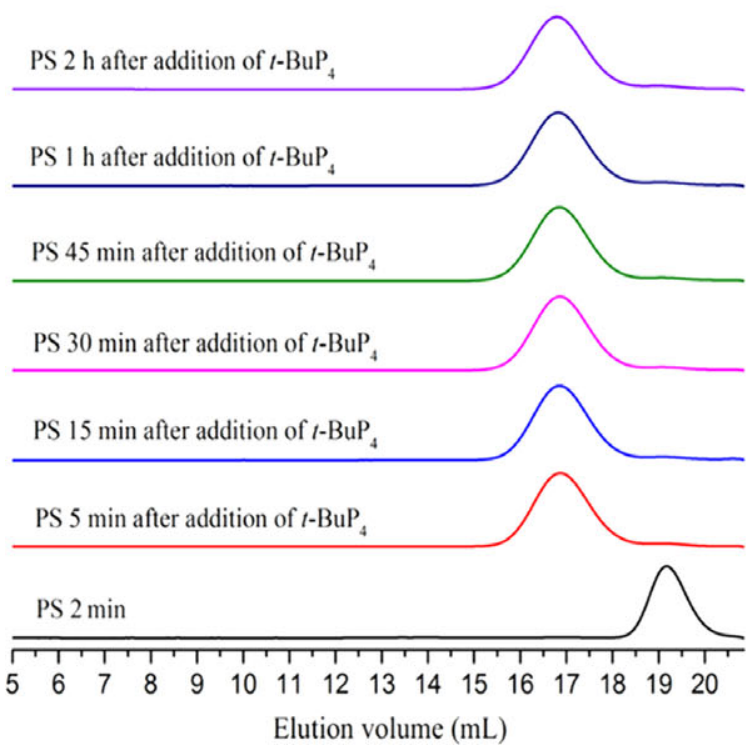

(B) ${ }^{*}$
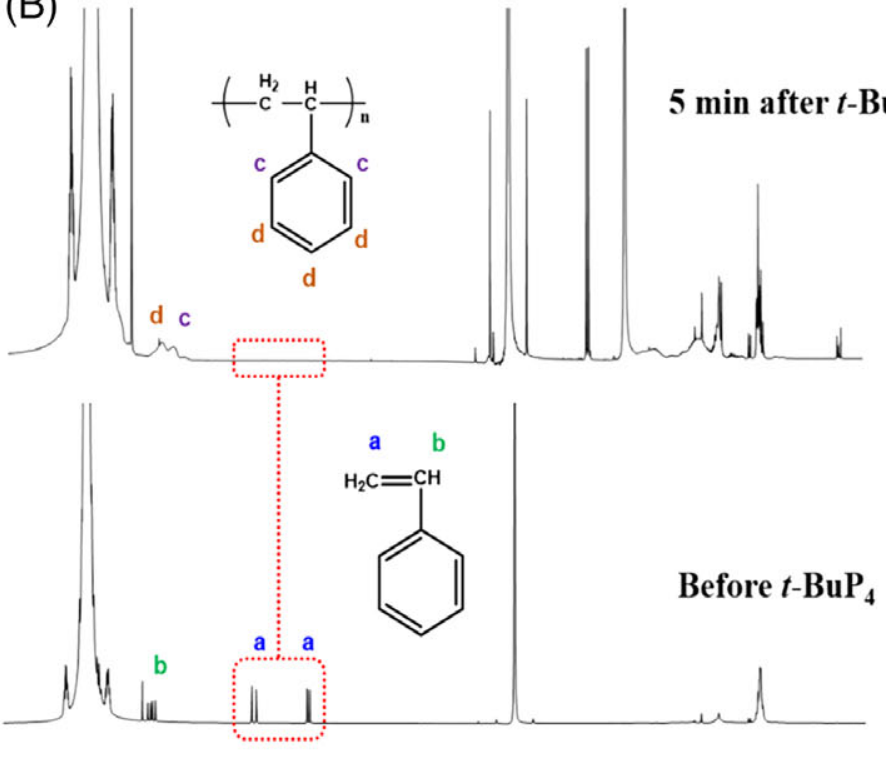

FIGURE 1 (A) Monitoring the polymerization of styrene via "seeding" and $t$-BuP 4 by SEC of withdrawn aliquots obtained at different time intervals (Table 1, PS-1, Entry 1); (B) ${ }^{1} \mathrm{H}-\mathrm{NMR}$ spectra taken $2 \mathrm{~min}$ after the initiation of the polymerization of styrene of styrene ("seeding" period) and $5 \mathrm{~min}\left(100 \%\right.$ conversion) after the addition of $t$-BuP $_{4}$. [Color figure can be viewed at wileyonlinelibrary.com]

flask, under high vacuum. Methanol (Sigma-Aldrich, 99.8\%) (terminating agent) was stored under high vacuum and used as received. $N, N, N^{\prime}, N^{\prime}$-Tetramethyl-1,2-ethylenediamine (TMEDA, Sigma-Aldrich, $\geq 99.5 \%$ ) was distilled over sodium mirror, diluted to an appropriate concentration in purified benzene and stored in precalibrated ampoules.

\section{Instruments}

The number-average molecular weight $\left(M_{\mathrm{n}}\right)$ and the polydispersity index $(\nexists)$ were determined via size exclusion chromatography (SEC) equipped with an isocratic pump, Styragel HR2 and HR4 columns in series $\left(300 \times 8 \mathrm{~mm}^{2}\right)$, a refractive index detector and THF as the eluent, at a flow rate of $1 \mathrm{~mL} \mathrm{~min}^{-1}$, at $30^{\circ} \mathrm{C}$. The calibration was performed using polystyrene (PS) standards $\left(M_{\mathrm{p}}: 370-422,0000 \mathrm{~g} \mathrm{~mol}^{-1}\right)$. Proton nuclear magnetic resonance $\left({ }^{1} \mathrm{H}-\mathrm{NMR}\right)$ spectroscopy measurements were carried out in $\mathrm{CDCl}_{3}$ (Sigma-Aldrich, 99.6\%) with a Brücker AV-500 spectrometer. The obtained spectra were used to calculate the monomer conversion as well as the microstructure of the synthesized polydienes after integration of the corresponding chemical shifts. Matrix-assisted laser desorption/ionization time-of-flight mass spectroscopy (MALDI-ToF MS) experiments were carried out using [1,8-dihydroxy-9(10H)-anthracenone; dithranol] as the matrix and silver trifluoroacetate (cationizing agent) on a Bruker Ultraflex III MALDI-TOF MS (Bruker Daltonik, Bremen, Germany). In general, mass spectra from 256 laser shots were accumulated and summed to produce a final spectrum.

\section{Polymerization in the Presence of Phosphazene Bases after "Seeding"}

All polymerizations were carried out via high vacuum techniques, using custom-made glass reactors, equipped with break seals for the addition of the reagents and constrictions for the removal of aliquots. ${ }^{13}$ A typical procedure is as follows. In an evacuated and $n$-BuLi washed glass reactor, containing $70 \mathrm{~mL}$ of benzene, $2.2 \mathrm{~mL}$ of styrene $(2 \mathrm{~g})$, and $0.25 \mathrm{mmol}$ of sec-BuLi were added at room temperature $\left(23{ }^{\circ} \mathrm{C}\right.$ ) (Table 1 , Entry 1). After $2 \mathrm{~min}$, an aliquot was taken and $0.25 \mathrm{mmol}$ of $t$ - $\mathrm{BuP}_{4}\left(p \mathrm{~K}_{\mathrm{a}}\right.$ in acetonitrile: 42.6$)$ was added and the reaction left to proceed. Small aliquots were withdrawn from the solution frequently in order to determine the conversion, the molecular weight, and the polydispersity. Finally, the reaction was quenched by adding methanol $(\sim 1 \mathrm{~mL})$ and the solution

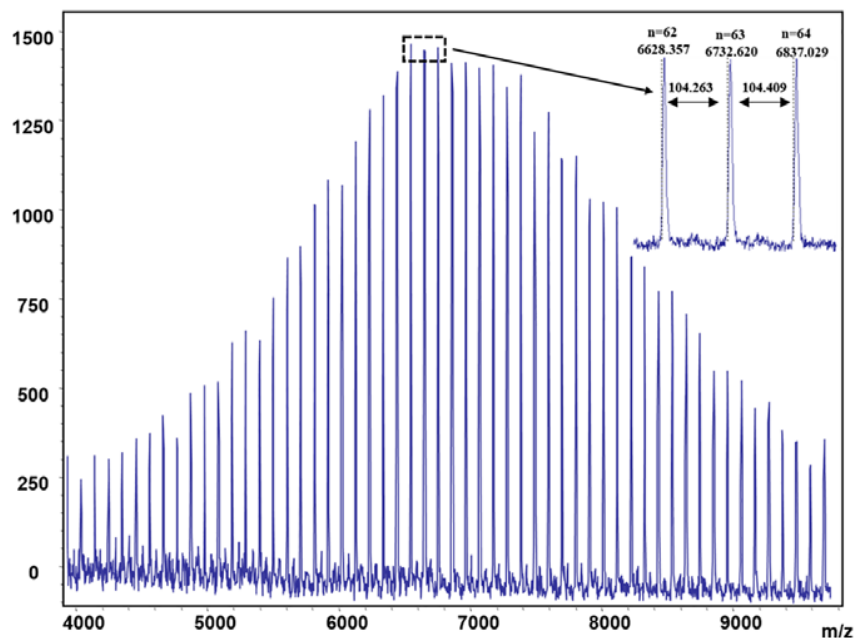

FIGURE 2 MALDI-ToF spectrum of PS synthesized via "seeding" and $t-\mathrm{BuP}_{4}$ as additive (Table 1, Entry 1). [Color figure can be viewed at wileyonlinelibrary.com] 
TABLE 2 Molecular Characteristics of PS Synthesized by Anionic Polymerization, "Seeding," and Use of Phosphazene Bases or TMEDA

\begin{tabular}{|c|c|c|c|c|c|c|c|}
\hline Entry & Sample & Additive & Additive/sec-BuLi ${ }^{\mathrm{a}}$ & $M_{\mathrm{n}}^{\text {target }}\left(\mathrm{g} \mathrm{mol}^{-1}\right)$ & $M_{\mathrm{n}}^{\mathrm{b}}\left(\mathrm{g} \mathrm{mol}^{-1}\right)$ & $\theta^{\mathrm{b}}$ & Time (100\% Conversion) (min) \\
\hline 1 & PS-1 & $t-\mathrm{BuP}_{1}$ & $1: 1$ & 9000 & 8600 & 1.05 & 110 \\
\hline 2 & PS-2 & $t-\mathrm{BuP}_{2}$ & $1: 1$ & 20,000 & 20,500 & 1.04 & 30 \\
\hline 3 & PS-3 & TMEDA & $1: 1$ & 8000 & 7600 & 1.05 & 130 \\
\hline
\end{tabular}

precipitated in a large excess of methanol. The white powder was collected and dried in a vacuum oven for 2 days $\left(M_{\mathrm{n}}=7200 \mathrm{~g} \mathrm{~mol}^{-1}, Ð=1.11\right)$. The same synthetic procedure was followed using $t-\mathrm{BuP}_{2}\left(p \mathrm{~K}_{\mathrm{a}}\right.$ in acetonitrile: 33.5), $t$ - $\mathrm{BuP}_{1}$ ( $p \mathrm{~K}_{\mathrm{a}}$ in acetonitrile: 26.9 ), and TMEDA as additives for the polymerization of styrene as well as in the case of the polymerization of 4MS and 1,3-butadiene via "seeding" with $t$-BuP 4 .

\section{Sequential Addition of Styrene or 1,3-Butadiene to the "Living" PS Synthesized via "Seeding"}

A typical procedure is as follows. To a "living" PS $\left(M_{\mathrm{n}}=4500 \mathrm{~g} \mathrm{~mol}^{-1}\right)$ (Table 3, Entry 2) synthesized by the previously described method, $1.4 \mathrm{~mL}$ of 1,3-butadiene was added and the polymerization left to proceed at room temperature $\left(23^{\circ} \mathrm{C}\right)$. The next day the polymerization quenched by adding methanol, the mixture precipitated in excess of methanol and finally collected and dried in a vacuum oven for 2 days $\left(M_{\mathrm{n}, \mathrm{PB}}{ }^{\mathrm{NMR}}=1300 \mathrm{~g} \mathrm{~mol}^{-1}, \oplus=1.32\right)$. The same synthetic protocol was followed for the sequential copolymerization of 1,3-butadiene, using $t$ - $\mathrm{BuP}_{2}$ and $t$ - $\mathrm{BuP}_{1}$ phosphazene bases and also for the polymerization of styrene using $t-\mathrm{BuP}_{4}$.

\section{Polymerization of Styrene via "Seeding" Using "Living" PB as Macroinitiator}

The anionic polymerization of 1,3-butadiene was conducted in benzene with sec-BuLi as initiator using high-vacuum techniques in evacuated, $n$-BuLi washed and benzene rinsed glass reactors. A typical procedure is as follows, $2 \mathrm{~mL}$ of 1,3-butadiene and $1.24 \mathrm{~mL}$ ( $0.124 \mathrm{mmol}$ ) of sec-BuLi were added to $50 \mathrm{~mL}$ of benzene and the reaction left to proceed for $24 \mathrm{~h}$. After the polymerization of 1,3-butadiene, an aliquot was removed from the apparatus for molecular characterization by SEC $\left(M_{\mathrm{n} \text {,heor. }}=10,000 \mathrm{~g} \mathrm{~mol}^{-1}\right.$, $M_{\mathrm{n}, \mathrm{NMR}}=9300 \mathrm{~g} \mathrm{~mol}^{-1}, Ð=1.03$ ). Subsequently, $1 \mathrm{~mL}$ of styrene was added first, left to react with "living" PB for $10 \mathrm{~min}$ and then $0.124 \mathrm{mmol}$ of $t \mathrm{BuP}_{4}$ was added. The polymerization left to complete for $1 \mathrm{~h}\left(M_{\mathrm{n} \text {,theor. }}{ }^{\mathrm{PS}}=7300, M_{\mathrm{n}, \mathrm{SEC}}{ }^{\mathrm{PS}}=7000 \mathrm{~g} \mathrm{~mol}^{-1}\right.$, and $\bigoplus_{\text {diblock }}=1.06$ ).

\section{RESULTS AND DISCUSSION}

It has been shown that the rate of polymerization of styrene, initiated by carbanions, is accelerated in the presence of Lewis bases, such us ethers and amines. ${ }^{18}$ In our previous report, the anionic polymerization of styrene, in benzene at room
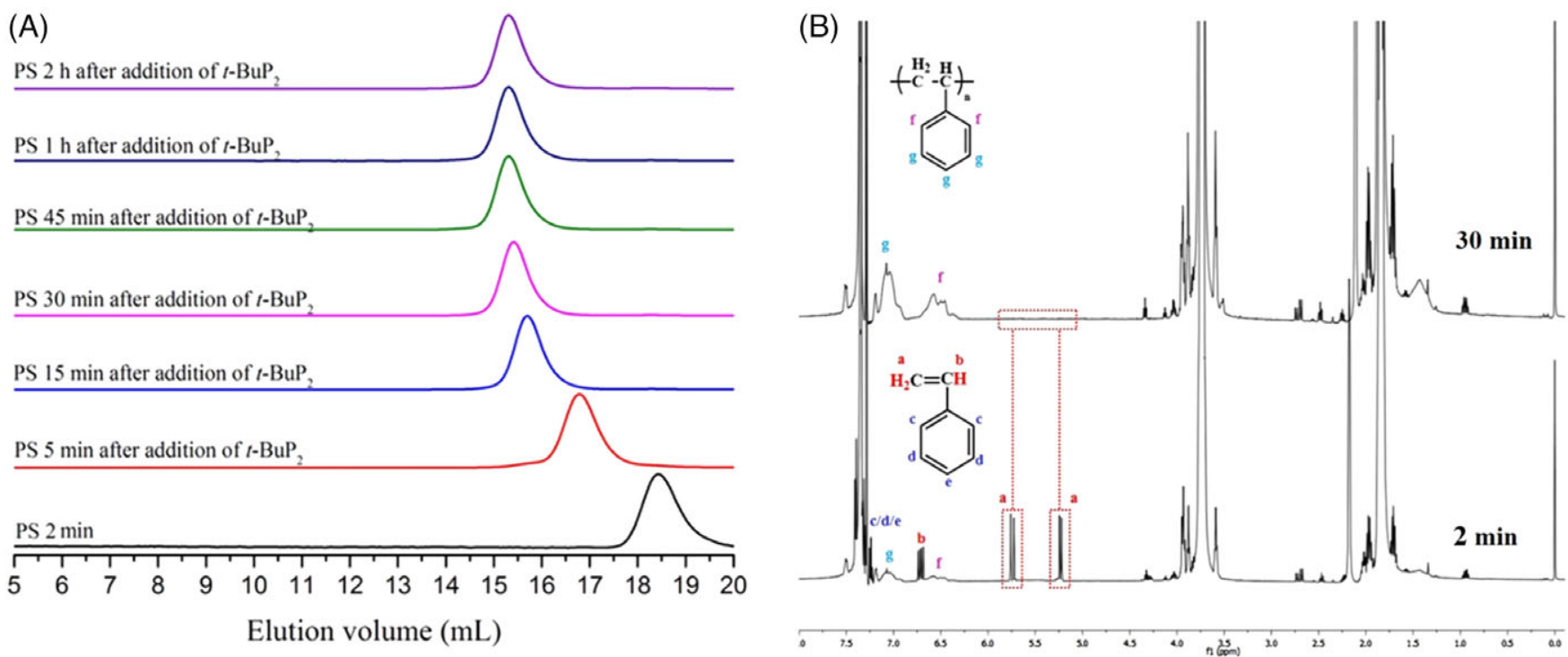

FIGURE 3 (A) Monitoring the polymerization of styrene via "seeding" and $t$-BuP 2 by SEC of withdrawn aliquots obtained at different time intervals. (B) ${ }^{1} \mathrm{H}$-NMR spectra taken 2 min after the initiation of the polymerization of styrene to form the "seeds" and 30 min $\left(100 \%\right.$ conversion) after the addition of $t-\mathrm{BuP}_{2}$. [Color figure can be viewed at wileyonlinelibrary.com] 
(A)
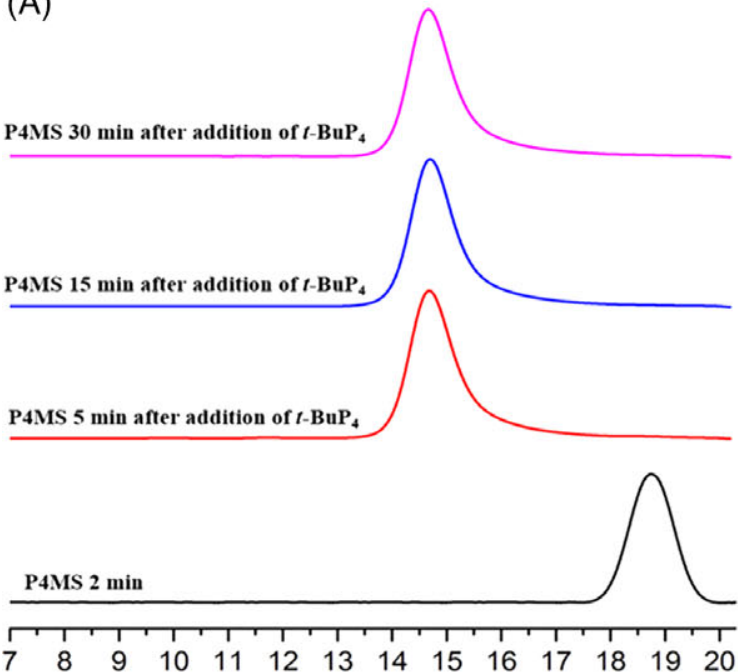

Elution volume $(\mathrm{mL})$

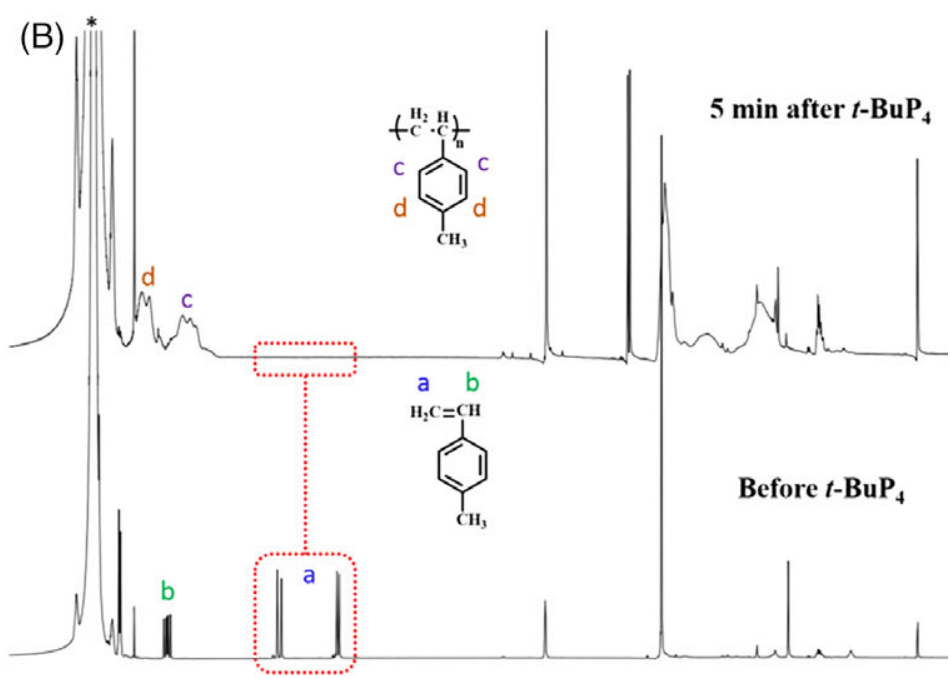

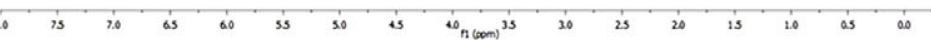

FIGURE 4 (A) Monitoring the polymerization of 4MS via "seeding" and $t$-BuP 4 by SEC of withdrawn aliquots obtained at different time intervals. (B) ${ }^{1} \mathrm{H}$ NMR spectra taken 2 min after the initiation of the polymerization of $4 \mathrm{MS}$ ("seeding" period) and $5 \mathrm{~min}$ (100\% conversion) after the addition of $t-\mathrm{BuP}_{4}$. [Color figure can be viewed at wileyonlinelibrary.com]

temperature $\left(23^{\circ} \mathrm{C}\right)$, with sec-BuLi in the presence of superbases $\left(t-\mathrm{BuP}_{4}, t-\mathrm{BuP}_{2}\right.$, and $t$-BuP $)$ with phosphazene/sec-BuLi: 0.5 $\left(t-\mathrm{BuP}_{2}\right.$ and $\left.t-\mathrm{BuP}_{1}\right)$ and $1\left(t-\mathrm{BuP}_{4}, t-\mathrm{BuP}_{2}\right.$, and $\left.t-\mathrm{BuP}_{1}\right)$ ratios, was studied. ${ }^{25}$ In the case of $t-\mathrm{BuP}_{2}$ and $t-\mathrm{BuP}_{1}$, the results were comparable to the ones already published for Lewis bases. ${ }^{18}$ However, in the case of $t$ - $\mathrm{BuP}_{4}$ (1:1) although the polymerization was fast, it was uncontrolled leading to PS with broad polydispersity index $(\nexists>1.9)$ and 10 times higher molecular weight than the theoretical one. Indeed, sec-BuLi exists in the form of an equilibrium between unreactive aggregated species and ion pairs. Upon adding $t$ - $\mathrm{BuP}_{4}$, the ion pairs and the superbase generate free carbanions $\left\{\mathrm{sec}-\mathrm{Bu}^{-}\left[\left(t-\mathrm{BuP}_{4}\right) \mathrm{Li}^{+}\right]\right\}$of extremely high reactivity that initiate polymerization and propagate chains. However, unreactive aggregated species are probably involved progressively in the process and hence a loss of control in the molecular weight and polydispersity occurs. The same trend, $R_{p} \gg>R_{i}$ was observed, in new experiments, when different $t$-BuP 4 /sec-BuLi: $2.5,5,10$, and 20 molar ratios were used (Table S1, Fig. S1, Supporting Information). Next, we thought to use a well-known "trick" in anionic polymerization called "seeding," in order to balance $R_{i}$ with $R_{p}{ }^{36}$

\section{Polymerization in the Presence of Phosphazene Bases after "Seeding"}

First, styrene was left to polymerize in benzene, with sec-BuLi, only for 1-2 min to afford oligomers ("seeds") and not the final polymer. Subsequently, an equimolar amount of $t$-BuP 4 to secBuLi was added and the polymerization was left to proceed until full consumption of the monomer. Finally, methanol was added to terminate the reaction (Scheme 1). We used only $t$ - $\mathrm{BuP}_{4} / \mathrm{sec}$ $\mathrm{BuLi}=1$, since, similar results were obtained with other ratios (Table S1, Fig. S1, Supporting Information).

To explore the utility of this system we investigated the ability to target higher degree of polymerization (Table 1). In all cases, the final polymers were characterized by narrow molecular weight distribution $(\nexists \leq 1.11)$ and the molecular weights were similar to the targeted ones [Fig. 1(A)]. Interestingly, the polymerization reaction was completed $5 \mathrm{~min}$ after the addition of the $t$-BuP 4 as revealed by ${ }^{1} \mathrm{H}$ NMR spectroscopy [Fig. 1(B)].

The acceleration of the polymerization is attributed to the high reactivity of the $\sec -\mathrm{Bu}^{-}$free anions, while the "seeding"

TABLE 3 Molecular Characteristics of PS- $b$-PS' and PS- $b$-PB (Co)polymers (PS Synthesized via "Seeding" and Use of Phosphazene Bases [1:1 Molar Ratio to sec-BuLi]) by Sequential Monomer Addition

\begin{tabular}{|c|c|c|c|c|c|c|c|c|}
\hline Entry & Sample & PB & $M_{\mathrm{n}}^{\mathrm{PS} \text { a }}\left(\mathrm{g} \mathrm{mol}^{-1}\right)$ & $D_{\mathrm{PS}}^{\mathrm{a}}$ & $M_{\mathrm{n}}^{2 \text { nd block }}\left(\mathrm{g} \mathrm{mol}^{-1}\right)$ & $M_{\mathrm{n}}^{2 \text { nd block (theor.) }}\left(\mathrm{g} \mathrm{mol}^{-1}\right)$ & $\theta_{\text {tot }}{ }^{\mathrm{a}}$ & Time ( $100 \%$ conversion) (min) \\
\hline 1 & PS- $b$-PS & $t-\mathrm{BuP}_{4}$ & 4700 & 1.13 & $6000^{a}$ & 5000 & 1.09 & 5 \\
\hline 2 & PS- $b$-PB & $t-\mathrm{BuP}_{4}$ & 4500 & 1.11 & $1300^{b}$ & 5000 & 1.32 & - \\
\hline 3 & PS- $b$-PB & $t-\mathrm{BuP}_{2}$ & 22,000 & 1.04 & $25,300^{b}$ & 13,800 & 1.12 & 240 \\
\hline 4 & PS- $b-\mathrm{PB}$ & $t-\mathrm{BuP}_{1}$ & 8600 & 1.05 & $19,000^{b}$ & 10,000 & 1.09 & 480 \\
\hline
\end{tabular}

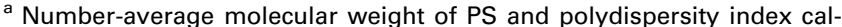
culated by SEC, using THF as a solvent and calibrated with PS standards.
${ }^{b}$ Number-average molecular weight of polybutadiene determined by ${ }^{1} \mathrm{H}$ NMR $(500 \mathrm{MHz})$ in $\mathrm{CDCl}_{3}$ at room temperature. 


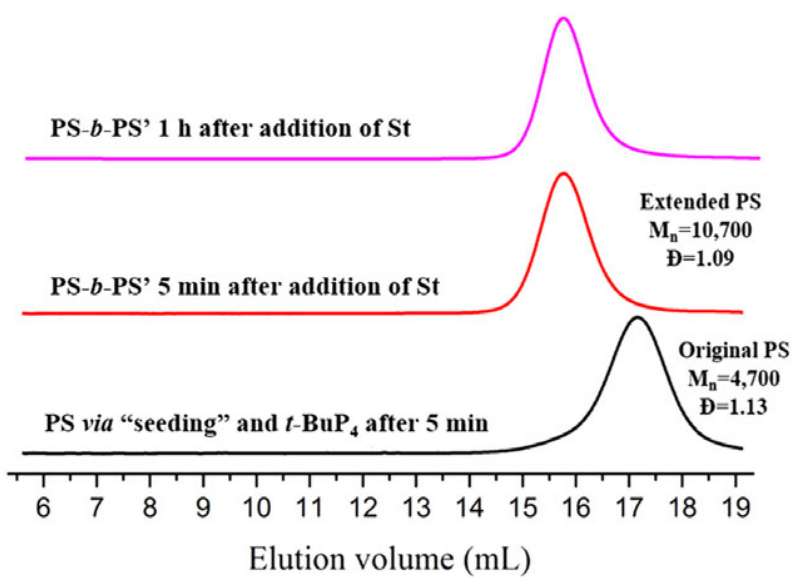

FIGURE 5 Monitoring the polymerization of styrene initiated by a "living" PS synthesized via "seeding" and $t$-BuP 4 . [Color figure can be viewed at wileyonlinelibrary.com]

is essential for balancing the propagation and initiation rates and avoid products with high-molecular-weight distribution. It should be noted that conventional anionic polymerization of styrene initiated by organolithium compounds, in hydrocarbon solvents, and at room temperature reaches 99\% conversion after $3 \mathrm{~h}^{37}$ The final product (Table 1, Entry 1) was further characterized by MALDI-ToF. As shown in Figure 2, only one narrow and symmetrical population was detected and the peak-to-peak mass difference of 104 corresponding exactly to the molar mass of the monomeric unit.

To examine how the basicity of the superbase affects the polymerization rate of styrene via "seeding", $t$ - $\mathrm{BuP}_{1}, t-\mathrm{BuP}_{2}$ along with TMEDA were applied under same conditions (additive/sec-BuLi molar ratio and solution concentration) (Table 2). As expected, the final products were characterized by narrow molecular weight distributions $(\nexists \leq 1.05)$ and the theoretical molecular weights were in good agreement with the experimental ones. Nevertheless, when $t$ - $\mathrm{BuP}_{2}$ and $t-\mathrm{BuP}_{1}$ were used (Table 2, Entries 1 and 2), the polymerization completed after 30 and $110 \mathrm{~min}$, respectively (Fig. 3, Fig. S2), due to the lower basicity, compared to $t$ - $\mathrm{BuP}_{4}$, leading to a significant decrease of the propagating site reactivity. When TMEDA was used, the monomer was consumed after $130 \mathrm{~min}$, faster than the conventional anionic polymerization of styrene, due to the decrease or even elimination of the association of polymeric organolithium chain ends (Fig. S3). ${ }^{38}$

Based on these findings, we were interested to utilize our approach with other styrenic monomers bearing alkyl side groups, such as 4MS. The conventional polymerization of the aforementioned monomers is generally conducted at low temperatures $\left(0\right.$ to $-70{ }^{\circ} \mathrm{C}$ ) and terminated at low conversion, in order to avoid chain-transfer reactions, involving initiator or growing chain ends and the p-alkyl groups of the monomer and polymer. ${ }^{39}$ Interestingly, when "seeding" technique was employed for 4MS at room temperature $\left(23{ }^{\circ} \mathrm{C}\right)$, in the presence of equimolar amount of sec-BuLi and $t-\mathrm{BuP}_{4}$, the polymerization completed after $5 \mathrm{~min}$, following the same trend as in the case of styrene (Fig. 4). The final poly(4MS) was characterized by narrow distribution $(\nexists=1.12)$ and nearly predictable molecular weight $\left(M_{\mathrm{n}}^{\text {theor. }}=25,000 \mathrm{~g} \mathrm{~mol}^{-1}, M_{\mathrm{n}}^{\text {exper. }}=20,000 \mathrm{~g} \mathrm{~mol}^{-1}\right)$. Obviously, the activation energies of propagation and transfer to monomer/polymer are dramatically modified in the presence of $t$ - $\mathrm{BuP}_{4}$, favoring propagation over transfer to the point that the latter would not even detected.

The same protocol was also used for the homopolymerization of the 1,3-butadiene but the polymerization was uncontrolled $\left(\bigoplus=1.72, M_{\mathrm{n}}^{\text {theor. }}=20,000 \mathrm{~g} \mathrm{~mol}^{-1}, M_{\mathrm{n}}{ }^{\text {exper. }}=3200 \mathrm{~g} \mathrm{~mol}^{-1}\right)$ and the conversion was low (<40\%) even after $14 \mathrm{~h}$ (Fig. S4). This is probably due to spontaneous and isomerization destruction reactions which are common in "living" polydiene solutions in the presence of even mild polar additive as THF. ${ }^{40,41}$

\section{Sequential Addition of Styrene or 1,3-Butadiene to the "Living" PS Synthesized via Seeding}

The "livingness" of the PS synthesized via "seeding" with $t$-BuP 4 was verified by the sequential polymerization of a second monomer (Table 3). First, a new amount of styrene was added when the initial styrene was fully consumed ( $5 \mathrm{~min}$ after the addition of $t$ - $\mathrm{BuP}_{4}$ ). The SEC trace of the final product was shifted to lower elution volume with narrow distribution $(\nexists=1.09)$ (Fig. 5), while the second amount of styrene was also consumed in 5 min. Importantly, the total number average molecular weight of the extended PS $\left(M_{\mathrm{n}}{ }^{\text {exper. }}=10,700 \mathrm{~g} \mathrm{~mol}^{-1}\right)$ was practically the theoretical value $\left(M_{\mathrm{n}}^{\text {theor. }}=10,000 \mathrm{~g} \mathrm{~mol}^{-1}\right.$ ) (Table 3, Entry 1). Even though is impossible to implement kinetic studies due to the short period of time, all of the above features indicate the "living" character of the polymerization.

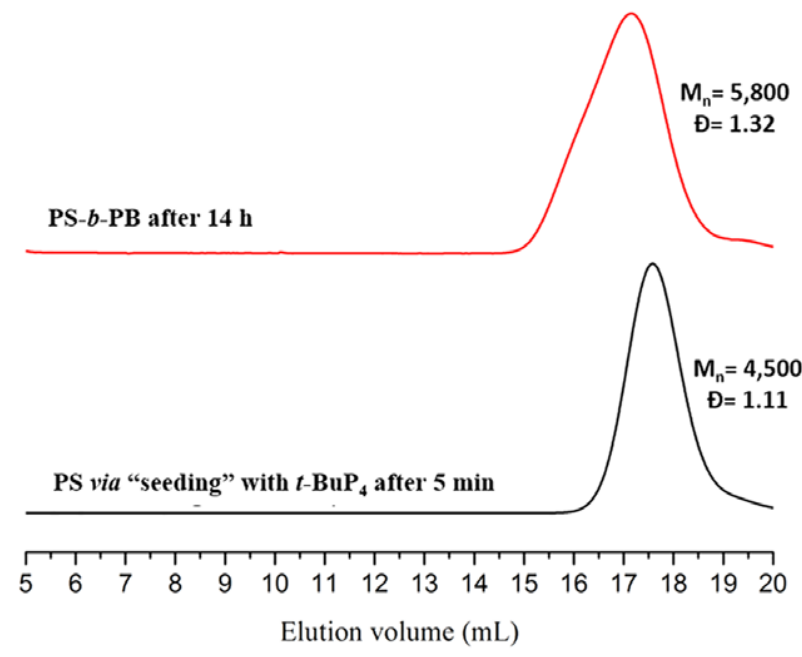

FIGURE 6 SEC traces of PS synthesized via "seeding" and $t-\mathrm{BuP}_{4}$ (down) and PS-b-PB (up) copolymer after sequential addition of 1,3-butadiene. [Color figure can be viewed at wileyonlinelibrary.com] 
(A)
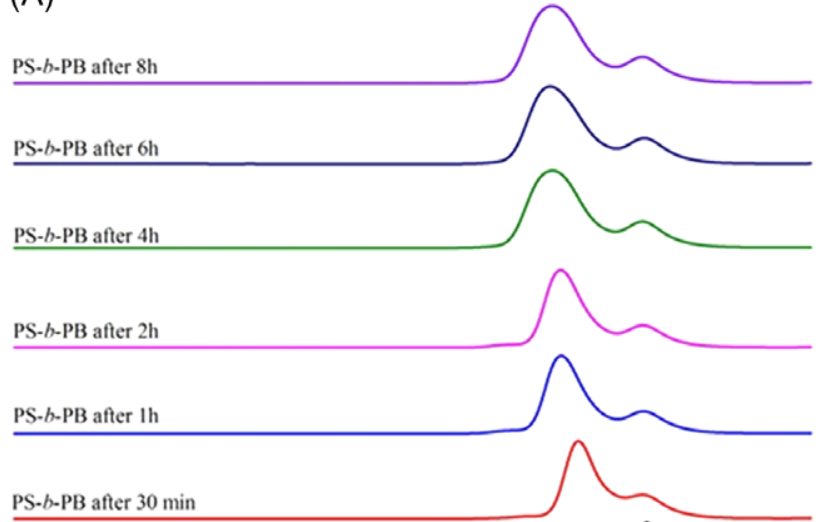

PS-b-PB after $30 \mathrm{~min}$

PS synthesized via seeding with $t-\mathrm{BuP}$, after $30 \mathrm{~min}$

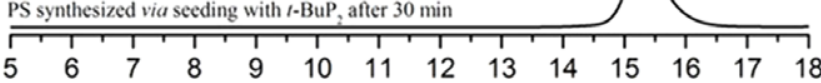

Elution volume $(\mathrm{mL})$

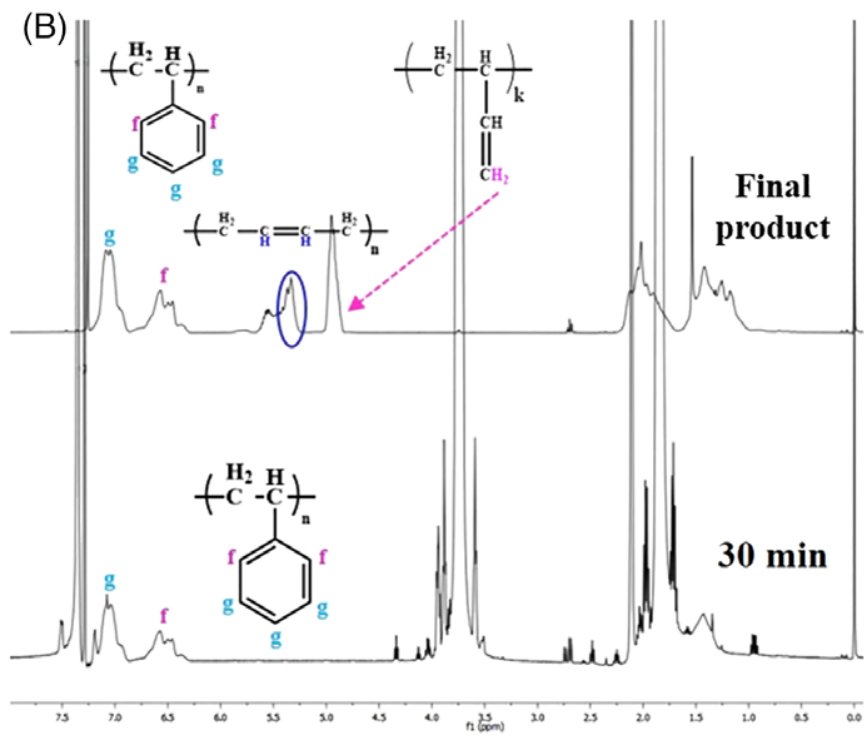

FIGURE 7 (A) Monitoring the copolymerization of PS- $b$-PB (PS macroinitiator via "seeding" and $t$-BuP ${ }_{2}$ by SEC of withdrawn aliquots obtained at different time intervals. (B) ${ }^{1} \mathrm{H}$ NMR spectra taken $30 \mathrm{~min}$ after the addition of $t$-BuP ${ }_{2}$ and of PS- $b$-PB final product. [Color figure can be viewed at wileyonlinelibrary.com]

In addition, 1,3-butadiene was utilized as the second monomer with PS as macroinitiator synthesized via "seeding" with $t$-BuP 4 (Table 3, Entry 2). The final block copolymer showed relatively broad polydispersity $(\nexists=1.32)$, low monomer conversion $(<40 \%)$ and molecular weight $M_{\text {n,exper. }}{ }^{\mathrm{NMR}}=1300 \mathrm{~g} \mathrm{~mol}^{-1}$, while the targeted molecular weight for the second block was $5000 \mathrm{~g} \mathrm{~mol}^{-1}$ (Fig. 6). This uncontrolled polymerization is attributed to isomerization reactions as described above.

In the case of 1,3-butadiene, these undesirable reactions were reduced, but not eliminated, when "seeding" took place and $t$-BuP 2 was used as additive (Table 3, Entry 3). Styrene was first polymerized ("seeding" and $t$-BuP 2 ), after the complete consumption of the monomer $(30 \mathrm{~min})$ 1,3-butadiene was added. The polymerization completed after $4 \mathrm{~h}$ and the SEC trace of the final diblock copolymer showed a bimodal molecular weight distribution (Fig. 7). We assume that isomerization reactions are taking place upon addition of a few monomeric units of 1,3-butadiene and deactivate a minor percentage of the "living" PS, while the rest is capable to promote the formation of the block copolymer. The same trend was observed when $t$ - $\mathrm{BuP}_{1}$ was used except that the polymerization completed after $8 \mathrm{~h}$
(A)
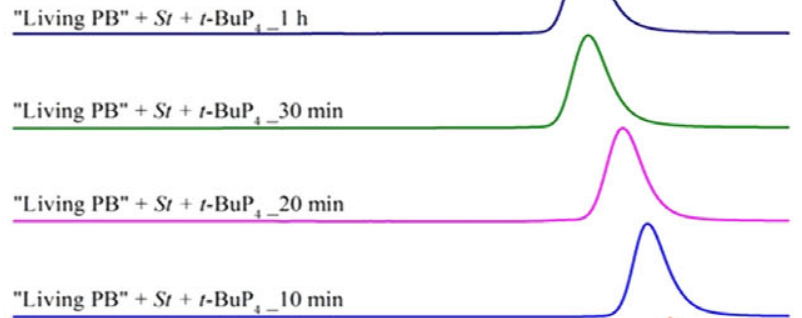

"Living $\mathrm{PB}^{\prime}+S t+t-\mathrm{BuP}_{4-} 10 \mathrm{~min}$

"Living PB" + St 10 min

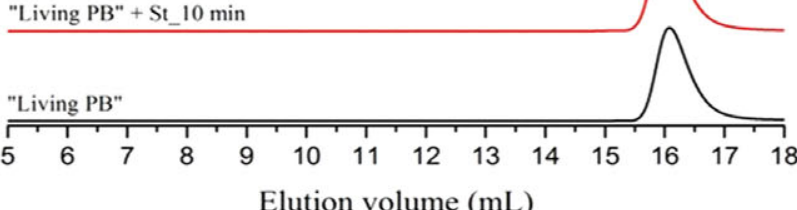

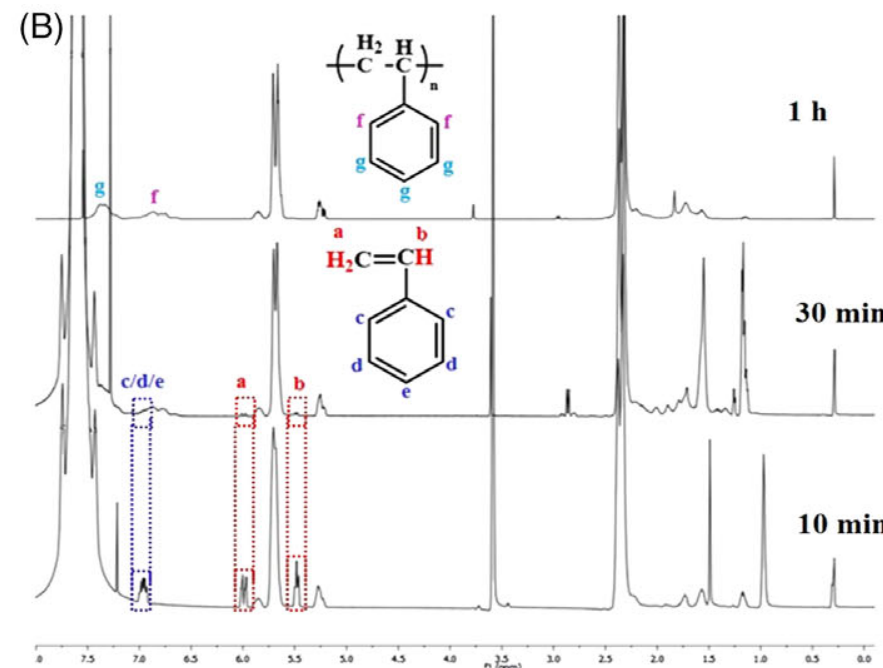

FIGURE 8 (A) Monitoring the polymerization of styrene initiated by a "living" polybutadiene and addition of $t$-BuP $\mathrm{P}_{4}$ after 10 min by SEC of withdrawn aliquots obtained at different time intervals. (B) ${ }^{1} \mathrm{H}$ NMR spectra taken $10 \mathrm{~min}, 30 \mathrm{~min}$, and $1 \mathrm{~h}$ after the addition of $t$-BuP 4 to a solution with "living" polybutadiene and St. [Color figure can be viewed at wileyonlinelibrary.com] 
(Table 3, Entry 4, Fig. S5). In all cases the vinyl content of the PB block, was equal to $60 \%$ wt, as determined by ${ }^{1} \mathrm{H}-\mathrm{NMR}$.

\section{Polymerization of Styrene via "Seeding" Using "Living" PB} as a Macroinitiator

To examine if the "seeding" technique in the presence of $t$ - $\mathrm{BuP}_{4}$ can be employed when a "living" macroanion is used instead of sec-BuLi, styrene was added in a solution of $\mathrm{PB}^{-} \mathrm{Li}^{+}$. After $10 \mathrm{~min}$, an equimolar amount of $t-\mathrm{BuP}_{4}$ to $\mathrm{PB}^{-} \mathrm{Li}^{+}$was added and the polymerization left to proceed. NMR spectra showed that after $30 \mathrm{~min}, 95 \%$ of the styrene was consumed [Fig. 8(B)]. The final diblock copolymer had a narrow polydispersity $(\nexists=1.06)$ and molecular weight equal to $16,300 \mathrm{~g} \mathrm{~mol}^{-1}$, close to the theoretical one $\left(M_{\text {n,diblock,theor }}=17,300 \mathrm{~g} \mathrm{~mol}^{-1}\right)$. The slower polymerization rate compared to the one obtained by seeding with sec-BuLi as initiator, can be attributed to association phenomena of $\mathrm{PB}^{-} \mathrm{Li}^{+}$in benzene. ${ }^{42}$ Nevertheless, the polymerization of the second block is still faster than the conventional anionic polymerization of styrene.

\section{CONCLUSIONS}

In summary, when a strong phosphazene base $\left(t-\mathrm{BuP}_{4}\right)$ is used as a promoter in anionic polymerization initiated by an organolithium compound, the polymerization is extremely fast but uncontrolled due to the high reactivity of the formed carbanions. In order to overcome this drawback, we report a facile method by combining phosphazene bases, organolithium initiator, and the "seeding" technique. Specifically, the addition of $t-\mathrm{BuP}_{4}$ after the formation of oligomers (seeds) led to the ultrafast anionic polymerization of styrene. All the monomers were consumed after only $5 \mathrm{~min}$ and the obtained homopolymers exhibit the desired molecular weights and narrow polydispersity. This method was successfully employed for the polymerization of 4MS in a hydrocarbon solvent at room temperature, where the polymerization rate was extremely fast thus suppressing potential chain-transfer reactions to the $p$-methyl group. The further addition of styrene to the $\mathrm{PS}^{-}\left[\left(t-\mathrm{BuP}_{4}\right) \mathrm{Li}^{+}\right]$confirmed the "livingness" of our system, since PS- $b$-PS' was obtained with controlled molecular characteristics after $5 \mathrm{~min}$. Preliminary experiments on the polymerization of 1,3-butadiene showed that this strategy is not suitable for the controlled synthesis of polydienes due to isomerization reactions. To conclude, this novel method might have an impact not only on academia but also in the industry since well-defined polymers are produced within minutes rendering the manufacturing process more cost-effective.

\section{ACKNOWLEDGMENT}

Research reported in this publication was supported by King Abdullah University of Science and Technology (KAUST).

\section{REFERENCES AND NOTES}

1 M. Szwarc, Nature 1956, 178, 1168.

2 M. Szwarc, M. Levy, R. Milkovich, J. Am. Chem. Soc. 1956, 78, 2656.
3 N. Hadjichristidis, A. Hirao, Anionic Polymerization: Principles, Practice, Strength, Consequences and Applications, Springer, Tokyo, Japan, 2015.

4 N. Hadjichristidis, S. Pispas, G. Floudas, Block Copolymers: Synthetic Strategies, Physical Properties and Applications, Wiley-Interscience, Hoboken, NJ, 2003.

5 G. Polymeropoulos, G. Zapsas, K. Ntetsikas, P. Bilalis, Y. Gnanou, N. Hadjichristidis, Macromolecules 2017, 50, 1253.

6 H. L. Hsieh, R. P. Quirk, Anionic Polymerization: Principles and Practical Applications, Marcel Dekker Inc., New York, 1996.

7 R. N. Young, R. P. Quirk, L. J. Fetters, Adv. Polym. Sci. 1984, $56,1$.

8 N. Hadjichristidis, H. latrou, M. Pitsikalis, J. W. Mays, Prog. Polym. Sci. 2006, 31, 1068.

9 R. P. Quirk, Applications of Anionic Polymerization Research. ACS Symposium Series, American Chemical Society, Washington, DC, 1998.

10 N. B. Bowden, Macromol. Chem. Phys. 2006, 207, 1917.

11 D. Baskaran, A. H. E. Müller, Prog. Polym. Sci. 2007, 32, 173.

12 H. Feng, X. Lu, W. Wang, N.-G. Kang, J. W. Mays, Polymers 2017, 9, 494.

13 N. Hadjichristidis, H. latrou, S. Pispas, M. Pitsikalis, J. Polym. Sci. Part A: Polym. Chem. 2000, 38, 3211.

14 M. Morton, A. A. Rembaum, J. L. Hall, J. Polym. Sci. Part A: Polym. Chem. 1963, 1, 461.

15 M. Van Beylen, S. Bywater, G. Smets, M. Szwarc, D. J. Worsfold, Adv. Polym. Sci. 1988, 86, 87.

16 Y. S. Yu, P. Dubois, P. Teyssié, R. Jérôme, Macromolecules 1997, 30, 7356.

17 M. Szwarc, M. Van Beylen, Ionic Polymerization and Living Polymers, Springer Science + Business Media Dordrecht, Netherlands, 1993.

18 F. J. Welch, J. Am. Chem. Soc. 1960, 82, 6000.

19 G. Helary, M. Fontanille, Polym. Bull. 1980, 3, 159.

20 M. Fontanille, Y. Gnanou, Macromolecular Engineering: Precise Synthesis, Materials Properties, Applications, Wiley- $\mathrm{VCH}$, Weinheim, Germany, 2007, p. 7.

21 S. Bywater, Y. Firat, P. E. Black, J. Polym. Sci. Part A: Polym. Chem. 1984, 22, 669.

22 G. Zapsas, D. Moschovas, K. Ntetsikas, S. Rangou, J.-H. Lee, E. L. Thomas, N. Zafeiropoulos, A. Avgeropoulos, J. Polym. Sci. Part B: Polym. Phys. 2015, 53, 1238.

23 R. Schwesinger, H. Schlemper, Angew. Chem. Int. Ed. 1987, 26, 1167.

24 R. Schwesinger, C. Hasenfratz, H. Schlemper, L. Walz, E.-M. Peters, K. Peters, H. G. von Schnering, Angew. Chem. Int. Ed. 1993, 32, 1361.

25 K. Ntetsikas, Y. Alzahrany, G. Polymeropoulos, P. Bilalis, Y. Gnanou, N. Hadjichristidis, Polymers 2017, 9, 538.

26 I. Weideman, R. Pfukwa, B. Klumperman, Eur. Polym. J. 2017, 93, 97.

27 B. Esswein, N. M. Steidl, M. Möller, Macromol. Rapid Commun. 1996, 17, 143.

28 H. Schlaad, H. Kukula, J. Rudloff, I. Below, Macromolecules 2001, 34, 4302.

29 J. Herzberger, K. Niederer, H. Pohlit, J. Seiwert, M. Worm, F. R. Wurm, H. Frey, Chem. Rev. 2016, 116, 2170.

30 A. Molenberg, M. Möller, Macromol. Rapid Commun. 1995, 16,449 . 
31 L. Zhang, F. Nederberg, J. M. Messman, R. C. Pratt, J. L. Hedrick, C. G. Wade, J. Am. Chem. Soc. 2007, 129, 12610.

32 L. Zhang, F. Nederberg, R. C. Pratt, R. M. Waymouth, J. L. Hedrick, C. G. Wade, Macromolecules 2007, 40, 4154.

33 H. Alamri, J. Zhao, D. Pahovnik, N. Hadjichristidis, Polym. Chem. 2014, 5, 5471.

34 S. Boileau, N. Illy, Prog. Polym. Sci. 2011, 36, 1132.

35 J. Zhao, D. Pahovnik, Y. Gnanou, N. Hadjichristidis, Macromolecules 2014, 47, 1693.
36 G. Y.-S. Lo, E. W. Otterbacher, A. L. Gatzke, L. H. Tung, Macromolecules 1994, 27, 2233.

37 D. J. Worsfold, S. Bywater, Can. J. Chem. 1960, 38, 1891. 38 R. Milner, R. N. Young, A. R. Luxton, Polymer 1983, $24,543$.

39 J. W. Mays, N. Hadjichristidis, Polym. Bull. 1989, 22, 471.

40 A. Gourdenne, P. Sigwalt, Eur. Polym. J. 1967, 3, 481.

41 D. J. Worsfold, S. Bywater, Can. J. Chem. 1964, 42, 2884.

42 M. Morton, L. J. Fetters, J. Polym. Sci. Part A: Polym. Chem. 1964, 2, 3311. 


\section{Graphical abstract}

\section{Ultrafast Phosphazene-Promoted Controlled Anionic Polymerization of Styrenic Monomers}

Konstantinos Ntetsikas, George Polymeropoulos, George Zapsas, Panayiotis Bilalis, Yves Gnanou and Nikos Hadjichristidis

The anionic polymerization of styrene by organolithium compounds in the presence of $t$-BuP $\mathrm{P}_{4}$ is uncontrolled. By using the "seeding technique," meaning that $t$ - $\mathrm{BuP}_{4}$ is added $2 \mathrm{~min}$ after the initiation, the polymerization of styrene and 4-methylstyrene was extremely fast ( $5 \mathrm{~min}$ ) and the final homopolymers exhibited narrow molecular weight distribution and controlled molecular characteristics. When $t$ - $\mathrm{BuP}_{2}$ and $t$ - $\mathrm{BuP}_{1}$ were used, the polymerization was also controlled but exhibited slower rates, due to the lower basicity.

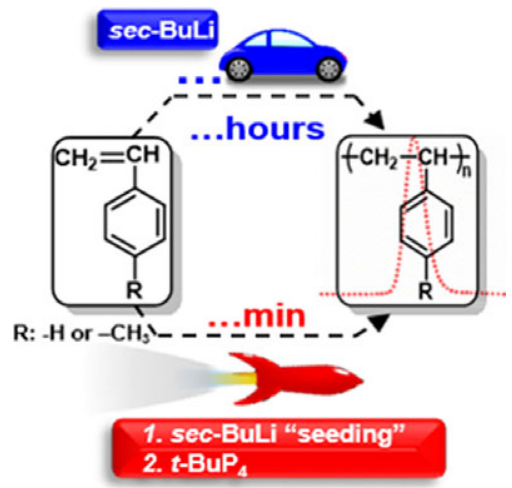

